\title{
Thrombotic Venous Diseases of the Liver
}

\author{
Timothy P. Sabol ${ }^{1}$, Marco Molina ${ }^{2}$ and George Y. Wu*3 \\ ${ }^{1}$ Department of Graduate Medical Education, Eastern Connecticut Health Network, Manchester Memorial Hospital, Manchester, \\ CT, USA; ${ }^{2}$ Department of Radiology, University of Connecticut Health Center, Farmington, CT, USA; ${ }^{3}$ Department of Medicine, \\ Division of Gastroenterology-Hepatology, University of Connecticut Health Center, Farmington, CT, USA
}

\begin{abstract}
Thrombotic venous diseases of the liver do not occur frequently, but when they do, they can present as difficult diagnostic and therapeutic challenges. The aim of this article is to review the epidemiology, pathogenesis, diagnosis, and therapeutic options of these serious vascular problems.

(C) 2015 The Second Affiliated Hospital of Chongqing Medical University. Published by XIA \& HE Publishing Ltd. All rights reserved.
\end{abstract}

\section{Portal vein thrombosis (PVT)}

PVT is an obstruction of blood flow into the liver. It is a rare vascular disorder of the liver, with an estimated incidence of $4 / 1,000,000$ per year and a prevalence of approximately $1 \%$ in the general population. ${ }^{1}$

The development of PVT is frequently due to a combination of local and systemic risk factors, which predispose patients to develop these disorders. Patients with PVT may present with a number of clinical symptoms.

\section{Presentation}

PVT can be subdivided into two types, acute and chronic. Symptoms in acute PVT develop within 60 days and include nausea, vomiting, diarrhea, loss of appetite, and abdominal pain. In addition, patients may present with fever, hematemesis, ascites, splenomegaly, melena, and hematochezia. ${ }^{2}$ Ascites tends to occur less frequently in presinusoidal thrombosis ${ }^{2,3}$ and is more commonly the result of venous congestion. ${ }^{2}$ PVT may be severe enough to lead to bowel infarction because of portal hypertension. ${ }^{3,4}$ Acute PVT can have a variable disease onset and clinical course (Table 1$).{ }^{3}$ Due to its rapid onset, there usually is no radiologic evidence of collateral circulation or portal hypertension in acute PVT. ${ }^{5}$

In contrast, patients with chronic PVT may be asymptomatic or have symptoms of jaundice, abdominal pain, cholangitis,

Keywords: Thrombosis; Hepatic veins; Portal hypertension.

Abbreviations: BCIS score, BCS-intervention-free survival prognostic score BCS, Budd-Chiari syndrome; CT, computed tomography; INR, international normalized ratio; IVC, inferior vena cava; JAK2, janus activated kinase 2; MPN, myeloproliferative neoplasms; MRI, magnetic resonance imaging; PAI-1, plasminogen activator inhibitor-1; PI, prognostic index; PVT, portal vein thrombosis; TIPS, transjugular intrahepatic portosystemic shunt; US, United States. Received: 26 April 2015; Revised: 01 June 2015; Accepted: 03 June 2015 DOI: $10.14218 / \mathrm{JCTH} .2015 .00014$.

* Correspondence to: George Y. Wu, Department of Medicine, Division of Gastroenterology-Hepatology, University of Connecticut Health Center, AM-045, Farmington, CT 06001, USA. Tel: +1-800-535-6232; +1-860-679-7692, Fax: +1-860-679-3159, E-mail: wu@uchc.edu hypersplenism, ascites, portal hypertension, variceal bleeding, and venous collateral circulation. By definition, the symptoms in the chronic condition develop over more than 60 days. $^{5}$

\section{Risk factors}

PVT has been linked with preexisting myeloproliferative disorders. ${ }^{3}$ One study found that primary myeloproliferative disorders were a major contributing factor in PVT. ${ }^{6}$ In these disorders, the most common mutation in cell signaling involves activation of tyrosine kinases, which results in marrow progenitor proliferation that is independent of growth factors and outside of typical cell growth control mechanisms. Since cell differentiation is not affected, proliferation of one or more mature blood elements occurs. Polycythemia vera, essential thrombocythemia, and primary myelofibrosis are the most frequent causes of PVT, likely via the janus activated kinase 2 (JAK2) pathway. ${ }^{3}$ In these cases of myeloproliferative disorders, the need for hematopoietic growth factors or erythropoietin is decreased due to stimulation of the JAK2 signaling pathway. In turn, hematocrit and red cell mass increase, which then cause decreased circulation and thrombotic events due to hyperviscosity. This may affect portal venous circulation. Late myeloproliferative disease may be associated with marrow fibrosis and compensatory enlargement of the liver and spleen secondary to extramedullary hematopoiesis. Increased platelet size has also been noted, which may impair function and increase bleeding risk. Patients with this disorder may have increased risk for both thrombosis and bleeding, as described previously. $^{3}$

Other risk factors of PVT are associated with antiphospholipid syndrome, and these include hereditary protein $C$ deficiency, factor V Leiden, ${ }^{4,7}$ prothrombin G20210A, ${ }^{7}$ and protein $\mathrm{S}$ deficiency. Single or multiple prothrombotic disorders or local abnormalities within the venous structures that create turbulence from blood flow may also contribute to PVT. ${ }^{6}$

Recently, the V617F mutation in JAK2 was found in a significant percentage of patients with myeloproliferative disorders, ${ }^{8,9}$ and this mutation was identified as one of the major predisposing factors associated with the development of PVT. This mutation seems to affect hematopoietic stem cells, leading to the development of a myeloproliferative disorder and subsequent low flow states. ${ }^{8}$

In another recent study, Smalberg et al. demonstrated a link between the $46 / 1$ haplotype and both JAK2V617Fpositive splanchnic vein thrombosis and JAK2V617F-negative splanchnic vein thrombosis with myeloproliferative neoplasms (MPN). ${ }^{10}$ The $46 / 1$ haplotype was not found in patients who did not have a myeloproliferative disorder. The 
Table 1. Risk factors for portal vein thrombosis and Budd-Chiari syndrome ${ }^{2,4,6,36,47-49}$

\begin{tabular}{ll}
\hline Risk factors & Associated conditions \\
\hline Protein C deficiency & Myeloproliferative disorders \\
Factor V leiden & Prior abdominal surgeries \\
Protein S deficiency & Postsurgical thrombosis \\
Oral contraceptive use & Cirrhosis \\
JAK2 mutation & Neoplasm \\
Homocysteine & Pancreatitis \\
Antiphospholipid syndrome & $\begin{array}{l}\text { Inflammatory conditions } \\
\text { of the abdomen }\end{array}$ \\
Antithrombin III deficiency & $\begin{array}{l}\text { Abdominal Infections } \\
\text { (sepsis) }\end{array}$ \\
Pregnancy & Ascites \\
Diaphragmatic compression & \\
Paroxysmal nocturnal & \\
hemoglobinuria &
\end{tabular}

study recommended screening JAK2V617F in patients with splanchnic vein thrombosis in the background of SVT-related MPN. Patients with MPN should be evaluated for the 46/1 haplotype despite being JAK2-negative because the 46/1 haplotype may confer a favorable outcome for SVT in these patients. ${ }^{10}$ In Western countries and in China, the literature appears to agree that JAK2V617F testing should be routinely performed in patients with noncirrhotic and nonmalignant PVT. ${ }^{11-13}$ In China, however, it is generally unnecessary to investigate JAK2V617F mutations in PVT with cirrhosis because decreased velocity of portal flow is the most likely etiology underlying PVT. ${ }^{11}$

In patients with PVT and liver cirrhosis, decreased portal flow and changes in the structural components of the liver are the primary pathogenetic factors. However, as in the case of noncirrhotic patients, inherited, acquired, and local thrombophilic factors may contribute to the clinical presentation. ${ }^{14}$ The fibrinolysis, coagulation, and anticoagulation pathways can be affected in patients with liver cirrhosis. One study found an association between decreased levels of protein $C$, protein S, and an increase in D-dimer and the development of PVT in patients with liver cirrhosis. ${ }^{15}$ More recent studies have indicated that natural anticoagulants did not appear to have a role in the development of PVT in liver cirrhosis, particularly when the influence of liver function was removed. ${ }^{16-18}$ The severity of cirrhosis did appear to be correlated with an imbalance in coagulation factors. ${ }^{18}$ Comcomitant PVT and liver cirrhosis is frequently associated with the presence of hepatocellular carcinoma and poor outcomes. ${ }^{19}$ Decreased hepatic function and tumor spread throughout the liver can contribute to poor prognosis.

\section{Diagnosis}

Doppler ultrasound, magnetic resonance imaging (MRI), and computed tomography (CT) are frequently used imaging techniques to assist in the diagnosis of PVT. ${ }^{2}$ Doppler ultrasound is the first line imaging modality used due to its general availability, low cost, and lack of ionizing radiation. The lumen of the portal vein can usually be easily visualized. Doppler imaging has the added benefit of determining the presence and direction of blood flow within vessels. In PVT, grey-scale ultrasound demonstrates intraluminal hyperechoic thrombus, often distending the vein (Fig. 1A). Color doppler or power doppler will demonstrate lack of color flow in an occluded portal vein (Fig. 1B). Spectral doppler waveforms will be unobtainable in bland thrombus. If color and spectral doppler flow is present within the thrombus, malignant thrombus would be considered. Chronic PVT manifest as multiple collateral vessels (cavernous transformation) in the porta hepatis. Ultrasound is of limited value in visualizing the superior mesenteric vein or mesenteric circulation, ${ }^{20}$ but this limitation of ultrasound can be overcome with CT or MRI.

Contrast enhanced CT and MRI are superior imaging techniques to evaluate the portal system and mesenteric circulation, as they can be visualized in their entirety. ${ }^{20,21}$ Bland thrombus in a contrast enhanced exam is hypodense on CT (Fig. 2A-2C) and hypointense on MRI (Fig. 3). Once cavernous transformation is present, the main and often right and left portal veins are difficult to identify and are replaced by numerous enhancing collaterals in the porta hepatis (Fig. 2D).

Doppler ultrasound is generally the imaging method of choice for demonstrating collateral vessels, cavernoma, or areas with solid hyperechoic substance within the portal vein or a branching vein. The portal vein may be distended. Doppler imaging is of primary benefit when evaluating the presence and direction of blood flow within vessels. It can also
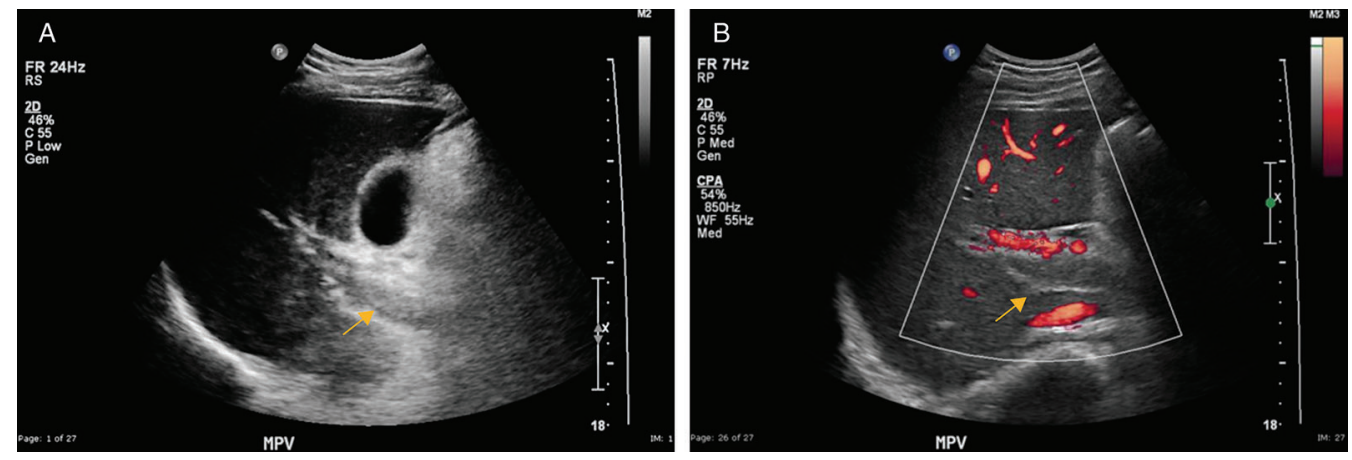

Fig. 1. Imaging characteristics of portal vein thrombosis. A, Greyscale ultrasound. Greyscale sonographic image demonstrates intraluminal echogenic material in the main portal vein, compatible with thrombus (yellow arrow); B, Power Doppler ultrasound. Power Doppler demonstrates thrombosis with lack of internal flow within the main portal vein (yellow arrow). 
Sabol T.P. et al: Portal vein thrombosis and Budd-Chiari syndrome
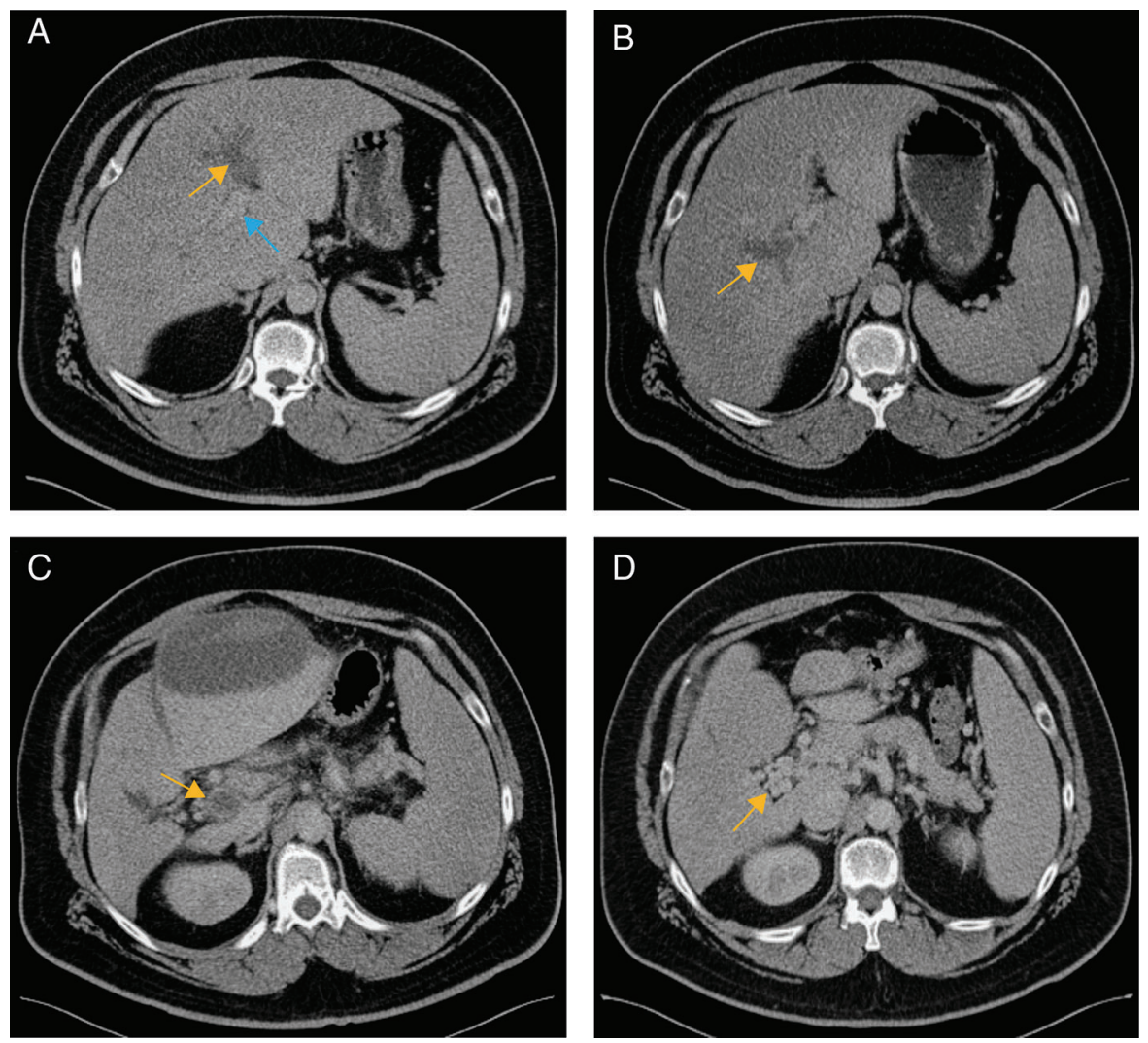

Fig. 2. Contrast-enhanced CT. A, Acute thrombosis of the umbilical segment of the left portal vein presenting as a hypodense filling defect (yellow arrow). Contrast opacification is seen proximally in the left portal vein (blue arrow); B, Acute thrombosis of the right portal vein presenting as a hypodense filling defect (yellow arrow) 2 months later in the same patient as Fig. 2A; C, Several months later in the same patient as Fig. $2 \mathrm{~A}$, thrombosis has propagated to the main portal vein and is similarly seen as a hypodense filling defect (yellow arrow). Incidentally, there is a subacute hematoma anteriorly after a liver biopsy; $D$, Follow-up CT 1 year later demonstrates cavernous transformation of the portal vein. Numerous tortuous venous collaterals have replaced the chronically thrombosed portal vein (yellow arrow).

be used to detect partially occlusive thrombus formations, particularly those involving tumor invasion of vessels. However, endoscopic ultrasound is of limited value in visualizing the intrahepatic portion of the portal vein and the distal superior mesenteric vein or for evaluating thrombus that extends into the mesenteric circulation. CT scanning can

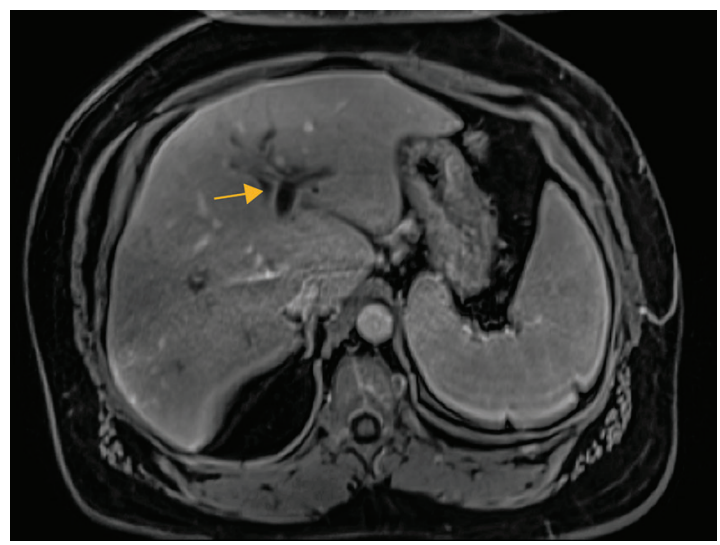

Fig. 3. Contrast-enhanced T1-weighted MRI. A fat-suppressed, volumetric interpolated breath hold examination (VIBE) MRI image in the same patient as Fig. 2A, demonstrates a hypointense filling defect in the left portal vein (yellow arrow) consistent with acute thrombosis. distinguish between acute versus chronic disease. CT may also be used to determine the extent of obstruction or if a neoplastic process is involved. Surrounding vasculature may be assessed if the thrombus extends into the superior mesenteric vein or splenic vein. ${ }^{22}$

\section{Treatment}

When portal venous tumor thrombosis involves the first or second branch of the portal vein, hepatic resection with portal vein thrombectomy is usually the procedure of choice. Other treatment options include cisplatin and 5-fluorouracil hepatic chemotherapy infusion, but results are limited. Due to tumor recurrence rates, liver transplantation is often unsuccessful. The use of 3D conformal radiation therapy (3D-CRT) has also been reported, but the data are insufficient to recommend this for general use. ${ }^{23}$

Medical treatment of patients with PVT consists primarily of anticoagulation agents. The use of heparin has been recommended when rapid onset of anticoagulation is required and to bridge patients until oral anticoagulation therapy can begin. For this purpose, intravenous and subcutaneous heparin appear to be equally effective. ${ }^{24}$ In general, patients with identified prothrombotic conditions should be maintained on anticoagulation for life. For patients that further progress to acute PVT on anticoagulation, percutaneous thrombolysis can be considered but secondary complications 
may develop. ${ }^{24}$ Although study populations to date have been small, the data have shown that anticoagulation is relatively safe and should be used as a first line treatment in patients with PVT and liver cirrhosis. ${ }^{25,26}$ Whether anticoagulation should be used in cases of liver cirrhosis has been controversial; and further investigations are warranted, particularly in the presence of comorbid conditions, such as esophageal varices and multiple coagulative disorders. ${ }^{14,25}$ One study estimated that partial to complete recanalization was achieved in approximately $60 \%$ of patients when anticoagulation was maintained with an international normalization ratio (INR) of 2.0 to 3.0. and an INR target of 2.5. Patients with thrombocytopenia with a platelet count less than $50 \times 10^{9} / \mathrm{L}$ may be at increased risk for bleeding complications. ${ }^{25}$ Some studies suggested that the overall balance between anticoagulant and procoagulant factors generally remained in proportion but were reduced in liver cirrhosis. ${ }^{27}$ There have been single subject case reports showing the possible benefit of factor Xa inhibitors in PVT, but large studies should to be conducted before these inhibitors are recommended for general clinical use. ${ }^{28-30}$

Patients who have medical complications such as variceal bleeding, refractory ascites, portal hypertension, or continued thrombosis despite anticoagulation should be considered for transjugular intrahepatic portosystemic shunt (TIPS) procedure. ${ }^{28,31}$ One study suggested that the benefit of anticoagulation therapy was limited to patients who had initiation of anticoagulation within 10 months of disease manifestation and had confirmed diagnoses. ${ }^{32}$

\section{Budd-Chiari syndrome (BCS)}

BCS, or hepatic vein thrombosis, is a condition caused by obstruction of the venous blood outflow from the liver. ${ }^{4,33,34}$ This may involve one or more of the hepatic veins and may or may not involve the inferior vena cava. ${ }^{33}$ Blood flow obstruction from cardiac disorders and sinusoidal obstruction syndrome, a nonthrombotic disorder involving either the central hepatic veins or sinusoids secondary to injury of the sinusoidal wall, are not included in BCS. BCS is a rare vascular disorder of the liver with an estimated incidence of $0.1-0.8$ / $1,000,000$ per year and a prevalence of $1.4-2.4 / 1,000,000$ per year in the US. ${ }^{1,34}$

\section{Presentation}

Patients with BCS typically present with abdominal pain, evidence of portal hypertension, hepatomegaly, and worsening liver function. ${ }^{3,4}$ Liver injury results from elevated intrahepatic pressure due to proximal thrombosis. Hepatic blood flow is unable to circumvent the blocked venous outflow. ${ }^{3}$ BCS appears histologically as areas of liver with centrilobular congestion and necrosis. In chronic cases, centrilobular fibrosis can develop. As with PVT, BCS can have a variable disease onset and clinical course (see Table 1$).^{3}$

\section{Risk factors}

Risk factors associated with the development of BCS are hereditary protein C deficiency, antiphospholipid syndrome, and factor $\mathrm{V}$ Leiden. ${ }^{4,35}$ Among these, protein $\mathrm{C}$ deficiency appears to be most commonly associated with hepatic vein thrombosis. ${ }^{6}$ Single or multiple prothrombotic disorders as well as local components within the venous structures may contribute to the development of $\mathrm{BCS}^{6}$ In a recent study, plasminogen activator inhibitor-1 (PAI-1) was found to be elevated in a subgroup of patients with BCS. It was suggested that increased levels of PAI-1 was related to fibrinolysis dysfunction in these patients. ${ }^{33}$ One case report found that use of oral contraceptives may be significant risk factor in patients with an underlying prothrombotic disorder. ${ }^{34}$

There is a growing body of evidence suggesting that patients with BCS should be screened for the JAK2V617F mutation. ${ }^{8,10}$ Since many patients with myeloproliferative disorders are not discovered with conventional medical techniques, this could be particularly helpful for patients with BCS with no known history of a myeloproliferative disorder. ${ }^{8}$ Recently, ethnic and geographic differences in the prevalence of JAK2V617F mutations in Western countries and in China were described. In Western countries, prothrombotic disorders are more likely to underlie BCS, whereas membranous obstruction appears to be a more prevalent cause in Asia, specifically China. Since the prevalence of BCS is lower in China than Western countries, ${ }^{11}$ the occurrence rates of the JAK2V617F mutations are lower as well. Therefore, JAK2V617F screening may not be indicated for patients with BCS in Asian countries. However, screening for this mutation may still be a useful tool in Western countries. ${ }^{11,13}$ Additionally, the 46/1 haplotype did appear to be an associative risk factor for JAK2V617F in BCS, but the low prevalence rate of this haplotype prevents it from being a cost-effective routine screen in Chinese patients. ${ }^{37,38}$

\section{Diagnosis}

Doppler ultrasound, MRI, and CT angiography are the most frequently used imaging techniques to assist in the diagnosis of BCS. ${ }^{2}$ Ultrasound in the acute stage can demonstrate hepatic vein thrombus as intraluminal hyperechogenicity with lack of color and spectral doppler flow. Secondary, less specific findings on ultrasound include gallbladder edema, pleural effusion, and ascites. Chronic cases may show portosystemic collateral circulation and splenomegaly. ${ }^{39}$ Contrast enhanced CT (Fig. 4A and 4B) or MRI can demonstrate hypodense or hypointense filling defects in the hepatic veins, respectively. The use of $C T$ and MRI may be a useful tool to distinguish BCS from liver cirrhosis through visualization of the caudate vein. Caudate vein dilatation and enhancement are due to intrahepatic collateral venous flow from other lobes. This was found by comparing MR images of BCS patients with control subjects. One study noted that $80 \%$ of patients with BCS had intrahepatic collateral veins. ${ }^{34}$ Furthermore, hypertrophy of the caudate lobe can compress the inferior vena cava (IVC). Typically, liver cirrhosis is associated with extrahepatic collateral venous circulation, whereas BCS may involve both extrahepatic and collateral intrahepatic circulations. The use of MRI may be a useful tool in distinguishing chronic BCS from liver cirrhosis by imaging the caudate vein. ${ }^{34}$

\section{Treatment}

There are a number of scoring indices that are predictive for the treatment of BCS. The Rotterdam Criteria appears to have the best discrimination index with respect to mortality over a 3 month period. This scale may be helpful in determining whether intervention is necessary. ${ }^{40,41}$ Similarly, the BCS TIPS prognostic index (PI) score demonstrates good accuracy with respect to mortality prediction. A relatively new scale, the BCS-intervention-free survival prognostic score (BCIS 

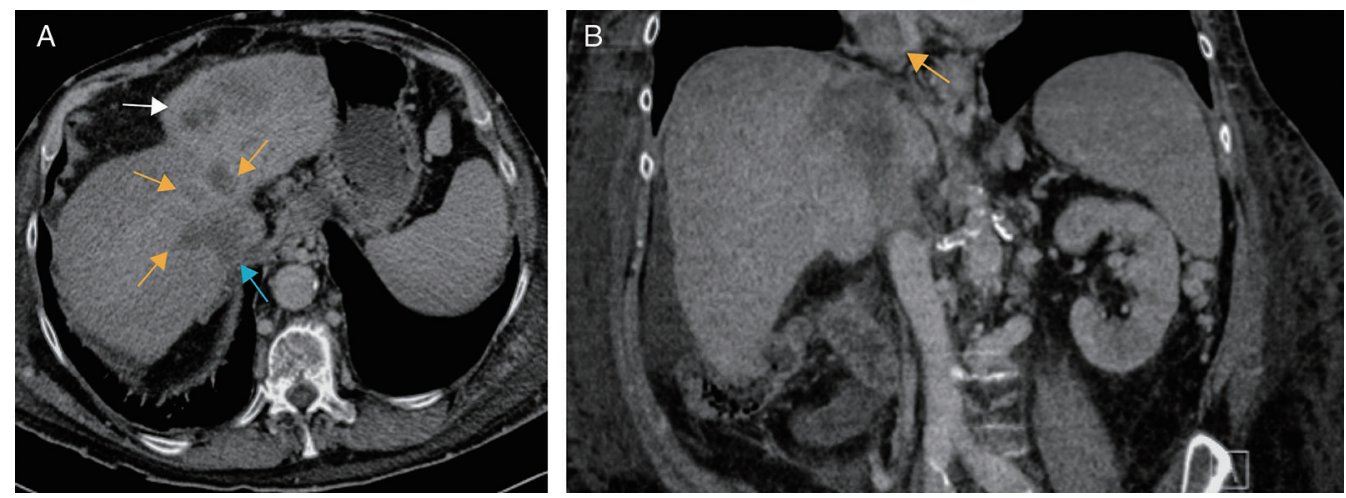

Fig. 4. Contrast-enhanced CT. A, Axial cut showing filling defects are present in the right, middle, and left hepatic veins (yellow arrows) and intrahepatic inferior vena cava (IVC) (blue arrow). Associated perfusional alterations of the liver are seen. Partially visualized is a hypodense mass in the anterior left hepatic lobe (white arrow); $B$, Coronal cut showing a hypodense thrombus involving the intrahepatic IVC extending into the right atrium (yellow arrow).

score), does not require variables such as INR, and this is significant because many patients are placed on anticoagulation therapy after diagnosis. The BCIS score has been shown to have similar discrimination as the BCS-TIPS PI score. ${ }^{41}$

Treatment for patients with BCS should be approached in a step-wise manner. Minimally invasive techniques should be used initially, and depending on response to individual treatment modalities, more invasive techniques can be considered if necessary. Patients should be evaluated based on effectiveness of less invasive techniques rather than on the severity of their medical status. ${ }^{20}$ First line treatment for these disorders remains anticoagulation therapy. ${ }^{20,42}$ Early anticoagulation can often lead to recanalization of the venous structures, and thus, the need for thrombolytic therapy, surgical thrombectomy, or transjugular intrahepatic portosystemic stent shunting can be avoided. ${ }^{42}$ Early diagnosis and implementation of therapy are important for recovery, and even earlier intervention may decrease the development of extrahepatic portal hypertension. More specifically, patients with prothrombotic disorders appear to benefit from the use of anticoagulants, as they decrease the development or reemergence of thrombosis. In effect, the increase in portal pressure may be avoided because of this decrease in thrombosis and development of collateral circulation. Patients left untreated after a prolonged course may not benefit from anticoagulation therapy. ${ }^{43}$ In one study with a small sample size, patients with liver cirrhosis did not respond as well to anticoagulation therapy as other population groups. In these cases, recanalization may require further interventional techniques. ${ }^{21}$ The effectiveness should be demonstrated with imaging techniques, ${ }^{42}$ and if found to be unsuccessful, stenting or TIPS procedures are alternatives. In patients that were unsuccessfully treated with anticoagulation, TIPS procedures appeared to be beneficial and improved survival rates. ${ }^{44}$ A TIPS procedure may be technically difficult to perform in some patients with portal cavernoma, ${ }^{45}$ but TIPS have still been performed in these cases. ${ }^{46}$ For recalcitrant cases, liver transplantation remains the only other viable option. ${ }^{42,44,47}$

\section{Conclusions}

The most common cause of obstructive venous disease of the liver is hypercoagulation. Symptoms are often nonspecific, with evidence of worsening liver function. Doppler ultrasound, $\mathrm{CT}$, and MRI can be helpful in making diagnoses. Treatment efforts should focus on ameliorating the underlying condition. Anticoagulation is a therapeutic mainstay that can promote recanalization.

\section{Conflict of interest}

None

\section{Author contributions}

Writing the article (TPS), providing the radiographic images and interpretation for the manuscript (MM), conceiving the idea for the review and editing the manuscript (GYW).

\section{References}

[1] Qi X, Jia J, Ren W, Yang M, De Stefano V, Wang J, et al. Scientific Publications on Portal Vein Thrombosis and Budd Chiari Syndrome: a Global Survey of the Literature. J Gastrointestin Liver Dis 2014;23:65-71.

[2] Sogaard KK, Astrup LB, Vilstrup H, Gronbaek H. Portal Vein Thrombosis; risk factors, clinical presentation and treatment. BMC Gastroenterol 2007;7:34. doi: 10.1186/1471-230X-7-34.

[3] Kumar V, Abbas AK, Fausto N, Aster JC. Robbins and Cotran Pathologic Basis of Disease. Philadelphia: Saunders Elsevier, 2010.

[4] Janssen HL, Meinardi JR, Vleggaar FP, van Uum SH, Haagsma EB, van der Meer FJ, et al. Factor $\mathrm{V}$ Leiden Mutation, prothrombin gene mutation, and deficiencies in coagulation inhibitors associated with Budd-Chiari Syndrome and portal vein thrombosis: results of a case-control study. Blood 2000;96: 2364-2368

[5] Parikh S, Shah R, Kapoor P. Portal Vein Thrombosis. Am J Med 2010;123: 111-119. doi: 10.1016/j.amjmed.2009.05.023.

[6] Denninger MH, Chait Y, Casadevall N, Hillaire S, Guillin MC, Bezaud A, et al. Cause of Portal or Hepatic Venous Thrombosis in Adults: The Role of Multiple Concurrent Factors. Hepatology 2000;31:587-591.

[7] Qi X, Ren W, De Stefano V, Fan D. Associations of Coagulation Factor V Leiden and Prothrombin G20210A Mutations With Budd-Chiari Syndrome and Portal Vein Thrombosis: A Systematic Review and Meta-analysis. Clin Gastroenterol Hepatol 2014;12:1801-1812.e7. doi: 10.1016/j.cgh.2014.04.026.

[8] Patel RK, Lea NC, Heneghan MA, Westwood NB, Milojkovic D, Thanigaikumar $\mathrm{M}$, et al. Prevalence of the Activating JAK2 Tyrosine Kinase Mutation V617F in the Budd-Chiari Syndrome. Gastroenterology 2006;130:2031-2038. doi: 10.1053/j.gastro.2006.04.008.

[9] Goulding C, Uttenthal B, Foroni L, Duke V, Traore A, Kottaridis P, et al. The JAK2V617F tyrosine kinase mutation identifies clinically latent myeloproliferative disorders in patients presenting with hepatic or portal vein thrombosis. Int J Lab Hematol 2008;30:415-419. doi: 10.1111/j.1751-553X.2007. 00973.x.

[10] Smalberg JH, Koehler E, Murad SD, Plessier A, Seijo S, Trebicka J, et al. The JAK2 46/1 Haplotype in Budd-Chiari Syndrome and Portal Vein Thrombosis. Blood 2011;117:3968-3973. doi: 10.1182/blood-2010-11-319087. 
[11] Oi X1, Yang Z, Bai M, Shi X, Han G, Fan D. Meta-analysis: the significance of screening for JAK2V617F mutation in Budd-Chiari syndrome and portal venous system thrombosis. Aliment Pharmacol Ther 2011;33:1087-1103. doi: 10.1111/j.1365-2036.2011.04627.x

[12] Qi X, Wu F, He C, Fan D, Han G. Thrombotic risk factors in Chinese nonmalignant and noncirrhotic patients with portal vein thrombosis: an observational study with a systematic review of the literature. Eur J Gastroenterol Hepatol 2015;27:77-83. doi: 10.1097/MEG.0000000000000221.

[13] Dentali F, Squizzato A, Brivio L, Appio L, Campiotti L, Crowther M, et al. JAK2V617F mutation for the early diagnosis of $\mathrm{Ph}^{-}$myeloproliferative neoplasms in patients with venous thromboembolism: a meta-analysis. Blood 2009;113:5617-5623. doi: 10.1182/blood-2008-12-196014.

[14] Amitrano L, Guardacione M, Brancaccio V, Margaglione M, Manguso F, Iannaccone $L$, et al. Risk Factors and clinical presentation of portal vein thrombosis in patients with liver cirrhosis. J Hepatol 2004;40:736-741. doi: 10.1016/j.jhep.2004.01.001.

[15] Donglei Z, Jianyu H, Ning Y. Protein C and D-dimer are related to portal vein thrombosis in patients with liver cirrhosis. J Gastroenterol Hepatol 2010;25: 116-121. doi: 10.1111/j.1440-1746.2009.05921.x.

[16] Qi X, Chen H, Han G. Effect of antithrombin, protein C and protein S on portal vein thrombosis in liver cirrhosis: a meta-analysis. Am J Med Sci 2013;346: 38-44. doi: 10.1097/MAJ.0b013e31826485fc.

[17] Chen H, Qi X, He C, Yin Z, Fan D, Han G. Coagulation imbalance may not contribute to the development of portal vein thrombosis in patients with cirrhosis. Thromb Res 2013;131:173-177. doi: 10.1016/j.thromres.2012. 11.003.

[18] Tang W, Wang Y, Zhao X, Wang X, Zhang T, Ou X, et al. Procoagulant imbalance aggravated with falling liver function reserve, but not associated with the presence of portal vein thrombosis in cirrhosis. Eur J Gastroenterol Hepatol 2015;27:672-678. doi: 10.1097/MEG.0000000000000352.

[19] Plessier A, Sibert A, Consigny Y, Hakime A, Zappa M, Denninger MH, et al. Aiming at Minimal Invasiveness as a Therapeutic Strategy for Budd-Chiari Syndrome. Hepatology 2006;44:1308-1316. doi: 10.1002/hep.21354.

[20] Ponziani FR, Zocco MA, Campanale C, Rinninella E, Tortora A, Di Maurizio L, et al. Portal Vein Thrombosis: Insight into physiopathology, diagnosis, and treatment. World J Gastroenterol 2010;16:143-155. doi: 10.3748/wjg.v16. i2.143.

[21] Attali J, Huergue A, Loock M, Thiefin G, Marcus C, Long A. Computed tomography follow-up of acute portal vein thrombosis. Diagnostic and Interventional Imaging, 2014;95:579-585. doi: 10.1016/j.diii.2014.02.018.

[22] Qi X, Han G, He C, Yin Z, Guo W, Niu J, et al. CT features of non-malignant portal vein thrombosis: a pictorial review. Clin Res Hepatol Gastroenterol 2012;36:561-568. doi: 10.1016/j.clinre.2012.05.021.

[23] Tanaka Y, Nakazawa T, Komori S, Hidaka H, Okuwaki Y, Takada J, et al. Radiotherapy for patients with unresectable advanced hepatocellular carcinoma with invasion to intrahepatic large vessels: Efficacy and outcomes. J Gastroenterol Hepatol 2014;29:352-357. doi: 10.1111/jgh.12333.

[24] Hall TC, Garcea G, Metcalfe M, Bilku D, Dennison AR. Management of Acute Non-cirrhotic and Non-malignant Portal Vein Thrombosis: A Systematic Review. World J Surg 2011;35:2510-2520. doi: 10.1007/s00268-0111198-0.

[25] Delgado MG, Sijo S, Yepes I, Achecar L, Catalina MV, García-Criado A, et al. Efficacy and Safety of Anticoagulation on Patients With Cirrhosis and Portal Vein Thrombosis. Clin Gastroenterol Hepatol 2012;10:776-783. doi: 10. $1016 / \mathrm{j} . \mathrm{cgh} .2012 .01 .012$

[26] Chung JW, Kim GH, Lee JH, Ok KS, Jang ES, Jeong SH, et al. Safety, efficacy, and response predictors of anticoagulation for the treatment of nonmalignant portal vein thrombosis in patients with cirrhosis: a propensity score matching analysis. Clin Mol Hepatol 2014;20:384-391. doi: 10.3350/cmh.2014.20. 4.384.

[27] Qi X, De Stefano V, Li H, Dai J, Guo X, Fan D. Anticoagulation for the treatment of portal vein thrombosis in liver cirrhosis: A systematic review and meta-analysis of observational studies. Eur J Intern Med 2015;26:23-29. doi: $10.1016 /$ j.ejim.2014.12.002.

[28] Martinez M, Tandra A, Vuppalanchi R. Treatment of Acute Portal Vein Thrombosis by Nontraditional Anticoagulation. Hepatology 2014;60:425-426. doi: 10.1002/hep.26998.

[29] Pannach S, Babatz J, Beyer-Westendorf J. Successful treatment of acute portal vein thrombosis with rivaroxaban. Thromb Haemost 2013;110: 626-627. doi: 10.1160/TH13-05-0407.
[30] Lenz K, Dieplinger B, Buder R, Piringer P, Rauch M, Voglmayr M. Successful treatment of partial portal vein thrombosis (PVT) with low dose rivaroxaban. Z Gastroenterol 2014;52:1175-1177. doi: 10.1055/s-0034-1385171.

[31] Luca A, Miraglia R, Caruso S, Milazzo M, Sapere C, Maruzzelli L, et al. Shortand long-term effects of the transjugular intrahepatic portosystemic shunt on portal vein thrombosis in patients with cirrhosis. Gut 2011;60:846-852. doi: $10.1136 /$ gut.2010.228023.

[32] Senzolo M, Sartori T, Rossetto V, Burra P, Cillo U, Boccagni P, et al. Prospective evaluation of anticoagulation and transjugular intrahepatic portosystemic shunt for the management of portal vein thrombosis in cirrhosis. Liver Int 2012;32:919-927. doi: 10.1111/j.1478-3231.2012.02785.x.

[33] Hoekstra J, Guimaraes AH, Leebeek FW, Murad SD, Malfliet JM, Plessier A, et al. Impaired fibrinolysis as a risk factor for Budd-Chiari Syndrome. Blood 2010;115:388-395. doi: 10.1182/blood-2009-03-211557.

[34] Tang W, Zhang XM, Yang L, Mitchell DG, Zeng NL, Zhi ZH. Hepatic caudate vein in Budd-Chiari syndrome: Depiction by using magnetic resonance imaging. Eur J Radiol 2011;77:143-148. doi: 10.1016/j.ejrad.2009.06.026.

[35] Deltenre P, Denninger MH, Hillaire S, Guillin MC, Casadevall N, Briere J, et al. Factor V Leiden related Budd-Chiari Syndrome. Gut 2001;48:264-268. doi: 10.1136/gut.48.2.264.

[36] Akbas T, Imeryuz N, Bayalan F, Baltacioglu F, Atagunduz P, Mulazimoglu L, et al. A case of Budd-Chiari syndrome with Behcet's disease and oral contraceptive usage. Rheumatol Int 2007;28:83-86. doi: 10.1007/s00296-0070377-7.

[37] Wang H, Sun G, Zhang P, Zhang J, Gui E, Zu M, et al. JAK2 V617F mutation and $46 / 1$ haplotype in Chinese Budd-Chiari syndrome patients. J Gastroenterol Hepatol 2014;29:208-214. doi: 10.1111/jgh.12379.

[38] Qi X, Zhang C, Han G, Zhang W, He C, Yin Z, et al. Prevalence of the JAK2V617F mutation in Chinese patients with Budd-Chiari syndrome and portal vein thrombosis: a prospective study. J Gastroenterol Hepatol 2012; 27:1036-1043. doi: 10.1111/j.1440-1746.2011.07040.x.

[39] Zweibel WJ. Sonographic Diagnosis of Hepatic Vascular Disorders. Semin Ultrasound CT MR 1995;16:34-48.

[40] Montano-Loza AJ, Tandon P, Kneteman N, Baily R, Bain VG. Rotterdam score predicts early mortality in Budd-Chiari syndrome, and surgical shunting prolongs transplant free survival. Aliment Pharmacol Ther 2009;30:1060-1069. doi: 10.1111/j.1365-2036.2009.04134.x.

[41] Seijo S, Plessier A, Hoekstra J, Dell'era A, Mandair D, Rifai K, et al. Good Long-Term Outcome of Budd-Chiari Syndrome with a Step-wise Management. Hepatology 2013;57:1962-1968. doi: 10.1002/hep.26306.

[42] Condat B, Pessione F, Denninger MH, Hillaire SH, Valla D. Recent Portal or Mesenteric Venous Thrombosis: Increased Recognition and Frequent Recanalization on Anticoagulant Therapy. Hepatology 2000;32:466-470. doi: $10.1053 /$ jhep.2000.16597.

[43] Condat B, Pessione F, Hillaire S, Denninger MH, Guillin MC, Poliquin M, et al. Current Outcome of Portal Vein Thrombosis in Adults: Risk and Benefit of Anticoagulant Therapy. Gastroenterology 2001;120:490-497. doi: 10.1053/ gast. 2001.21209.

[44] Garcia-Pagan JC, Heydtmann M, Raffa S, Plessier A, Murad S, Fabris F, et al. TIPS for Budd-Chiari Syndrome: Long-term Results and Prognostics Factors in 124 Patients. Gastroenterology 2008;135:808-815. doi: $10.1053 / j$.gastro. 2008.05.051.

[45] Qi X, Han G, Yin Z, He C, Wang J, Guo W, et al. Transjugular intrahepatic portosystemic shunt for portal cavernoma with symptomatic portal hypertension in non-cirrhotic patients. Dig Dis Sci 2012;57:1072-1082. doi: 10.1007/s10620-011-1975-5.

[46] Han G, Qi X, He C, Yin Z, Wang J, Xia J, et al. Transjugular intrahepatic portosystemic shunt for portal vein thrombosis with symptomatic portal hypertension in liver cirrhosis. J Hepatol 2011;54:78-88. doi: 10.1016/j. jhep.2010.06.029.

[47] Mentha G, Giostra E, Majno PE, Bechstein WO, Neuhaus P, O'Grady J, et al. Liver transplantation for Budd-Chiari syndrome: A European study on 248 patients from 51 centres. J Hepatol 2006;44:520-528. doi: 10.1016/j.jhep. 2005.12.002.

[48] Minnema MC, Janssen HL, Niermeijer P, de Man RA. Budd-Chiari Syndrome: Combination of genetic defects and the use of oral contraceptives leading to hypercoagulability. J Hepatol 2000;33:509-512. doi: 10.1016/S0168-8278 (00)80290-1.

[49] Ferkolj I, Vrh-Jermancic J, Stabuc B. Fatal Hemorrhage Due to Thrombosis and Rupture of the Portal Vein and Hepatic Artery. Wien Klin Wochenschr 2009;121:537-539. doi: 10.1007/s00508-009-1179-6. 